\title{
Short time recovery from severe knee algodystrophy treated with ozone-oxygen autohemotherapy
}

\author{
Andrea Della Puppa, ${ }^{1}$ Marianno Franzini ${ }^{2}$ \\ 'Specialist in Anesthesia, Resuscitation and Pain Therapy, Scientific Society of Oxygen Ozone \\ Therapy, Gorle (BG); ${ }^{2}$ President SIOOT, Professor a.c. Oxygen-Ozone therapy, University of Pavia, \\ Pavia, Italy
}

\begin{abstract}
We report a case of a 30-year-old man with algodystrophy of the left knee, who had complete recovery after 6-week treatment with ozoneoxygen autohemotherapy.
\end{abstract}

\section{Case Report}

A 30-year-old man came to our attention one month after accidental trauma of the left knee. The patient was reporting pain on walking and standing up with numeric rating score for pain (NRS)=9, and 6-7 on resting. Physical examination showed swollen left knee with increased skin temperature, pain on deep pressure and light stiffness during movement of bending and extending.

Magnetic resonance imaging (MRI) of the left knee showed extensive bone marrow edema of the condilus tibialis (Figure 1). No lesions of muscle, ligaments, or cartilage, or free fluid in the articular cavity were found.

Patient was diagnosed with algodystrophy, and ozone-oxygen autohemotherapy was started immediately.

Ozone was generated by Medical 95 CPS Computerized Photometric System manufactured by Multiossigen (Gorle, Italy). Autohemotherapy Bags SAN03 CEE93/42 certified were used.

Treatments were given twice a week; ozone was mixed with blood,

Correspondence: Andrea Della Puppa, Scientific Society of Oxygen-Ozone Therapy, via Roma 69 , Gorle (BG), Italy.

$\mathrm{Tel} / \mathrm{Fax}:+39.035 .300903$.

E-mail: dellapuppaandrea@gmail.com

Key words: Ozone; Algodystrophy; Autohemotherapy.

Received for publication: 16 November 2016.

Accepted for publication: 13 December 2016.

CC Copyright A. Della Puppa and M. Franzini, 2016

Licensee PAGEPress, Italy

Ozone Therapy 2016; 1:6473

doi:10.4081/ozone.2016.6473

This article is distributed under the terms of the Creative Commons Attribution Noncommercial License (by-nc 4.0) which permits any noncommercial use, distribution, and reproduction in any medium, provided the original author(s) and source are credited. in agreement with the Scientific Society of Ozone 0xygen Therapy (SIOOT) protocol, ${ }^{1}$ by using $10,000 \mu \mathrm{g}$ dose for each infusion.

After the $4^{\text {th }}$ infusion pain was greately reduced, NRS $=3$ on activity and standing up and 1 during rest. Also swelling and movement impairement were reduced. After the $6^{\text {th }}$ treatment patient was pain free and the other clinical signs disappeared. However, ozone-oxygen autohemotherapy was continued until the $10^{\text {th }}$ session was completed.

At this point the MRI demonstrated resolution of the bone marrow edema (Figure 2). The patient was considered healed and ozone-oxygen autohemotherapy stopped.

At a later control, 6 months after ozone-oxygen autohemotherapy had been stopped, the patient was still pain free and in full activity.

\section{Dicussion}

Algodystrophy is charaterized by joint pain following trauma or surgery ${ }^{2}$ and it is a disease highly debilitanting and difficult to treat. Severe forms of algodydrtrophy may involve skin and soft tissue (complex regional pain syndrome type I), sometimes with nerve damage (complex regional pain syndrome type II).

The evolution of algodystrtrophy is very slow, but generally benign. However, pain can last for several months, or years, causing ditress, inhability and change in psychological status. Various different treatments, alone, or in association, including bisphosphonate, analgesic, local anethetics, physical therapy and neuromodulation have been proposed, with different, but not satisfactory, results. ${ }^{3,4}$

Recently a double-blind placebo controlled study showed the efficacy of neridronate to reduce pain of $50 \%$ at 40 days after treatment. This study represents, so far, the best-controlled clinical evidence of therapeutic effect.

Ozone-oxygen therapy is well known for its various applications in medicine, including vascular, inflammatory and nervous system degenerative disease, as well as intervertebral disc hernia, in agreement with the Scientific Society of Oxygen Ozone Therapy. ${ }^{5}$ Therefore, the use of ozone-oxygen in alogodystrophy seems to be rationale.

In this case ozone-oxygen autohemotherapy obtained a very remarkable effect in a short time. Ozone-oxygen reduced pain more than $70 \%$ on walking and standing up, and more than $85 \%$ on rest after 2 weeks. Moreover, pain disappeared after three weeks, with full recovery of patient at 6 weeks, and 6 months later.

\section{Conclusions}

This case suggests the need of more extensive controlled studies of ozone-oxygen autohemotherapy on algodystrophy, considering also the association with neridronate, for the best future therapeutic results. 

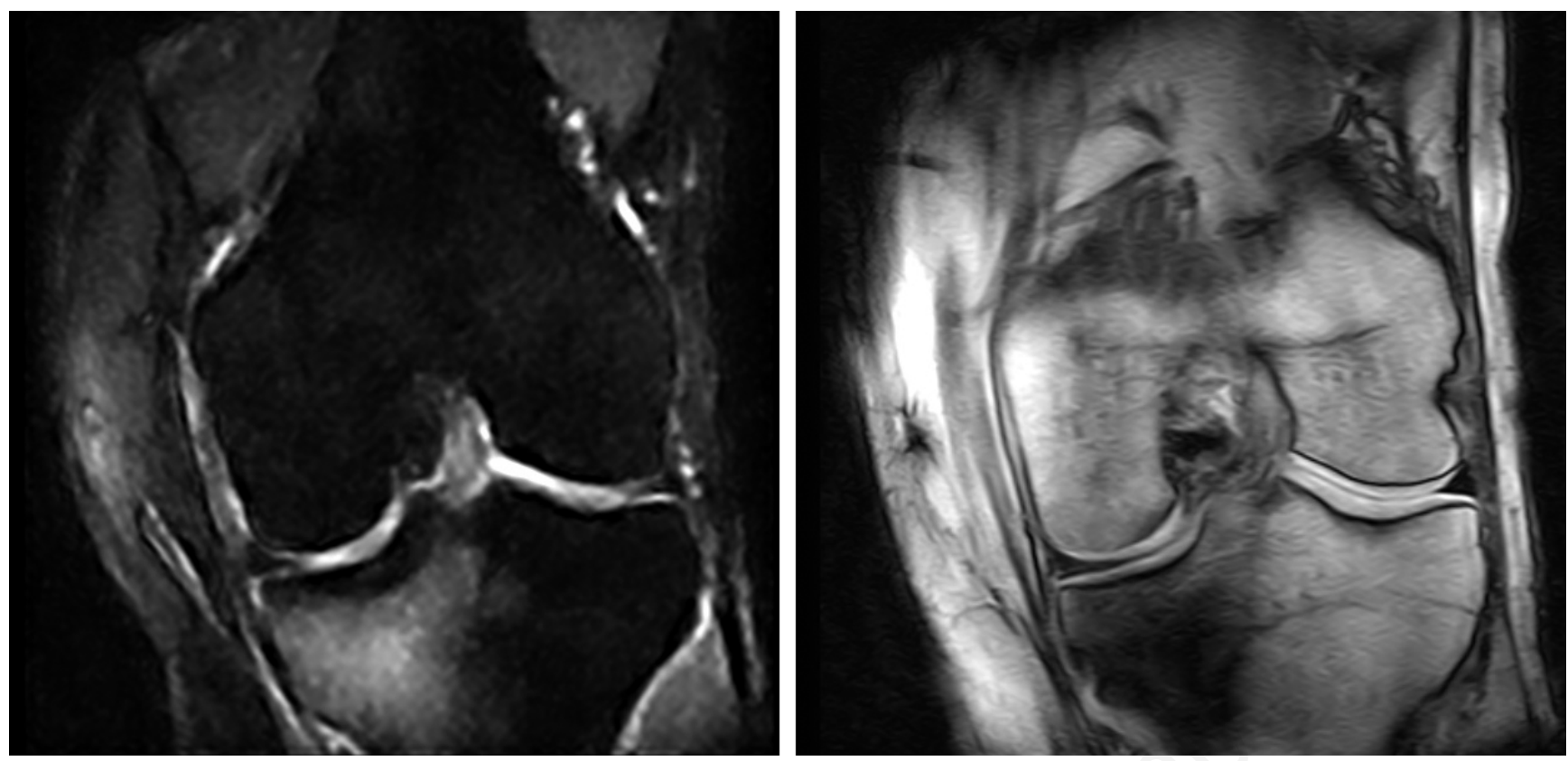

Figure 1. Magnetic resonance imaging of the left knee showing extensive bone marrow edema of the condylus tibialis.
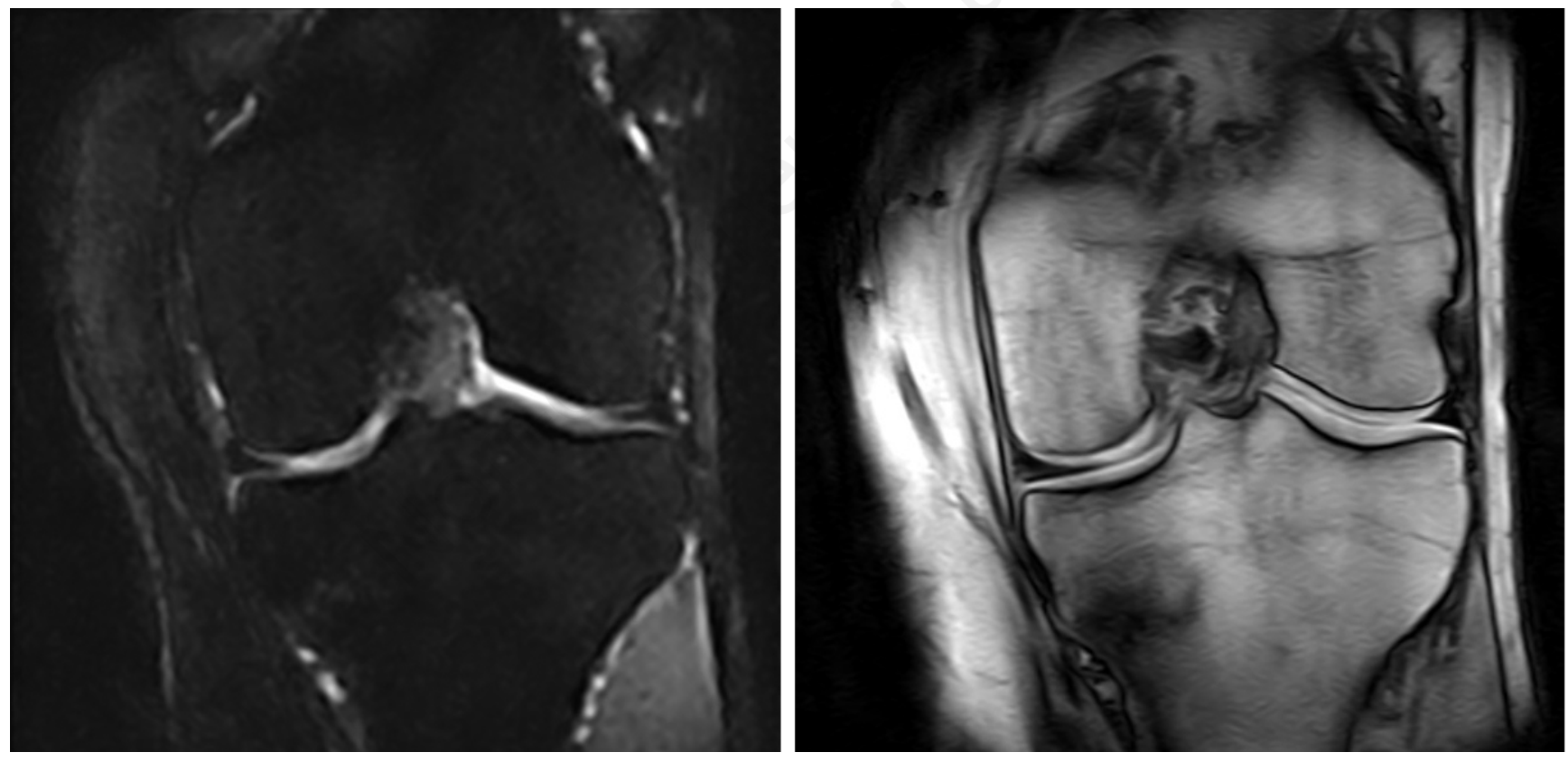

Figure 2. Magnetic resonance imaging showing resolution of the bone marrow edema.

\section{References}

1. Paoloni M, Di Sante L, Franzini M, et al. Intramuscular oxygen ozone therapy in the treatment of acute back pain with lumbar disc herniation. Spine 2009;34:1337-44.

2. de MosM, de Bruijn AG, Huygen FJ, et al. The incidence of complex regional pain syndrome: a population-based study. Pain 2007;129:12-20.
3. Tran de QH, Duong S, Bertini P, et al. Treatment of complex regional pain syndrome: a review of the evidence. Can J Anaesth 2010;57: 149-66.

4. Perez RS, Zollinger PE, Dijkstra PU, et al. Evidence based gudelines for complex regional syndrome type 1. BMC Neurol 2010; 31:10-20.

5. Franzini M. [Ossigeno ozono terapia: che cos'è e cosa fa]. [Book in Italian]. Gorle: SIOOT Società Scientifica di Ossigeno-Terapia; 2013. 